\title{
DEVEOLPMENT AND EVALUATION OF A TANGENTIAL HONEY - EXTRACTOR
}

\author{
Al-Rajhi M. A. ${ }^{*}$ and A. M. A. EL-Sheikha**
}

\section{ABSTRACT}

The honey extractor is an essential equipment, which any bee-keeper should have in order to extract the maximum quantity of honey from the combs. The tangential position of the combs inside the extractor is used for extracting the honey centrifugally by spinning honey out of the honeycombs after they have been uncapped. Honey is usually extracted by a manual extractor, which requires lots of effort and time. The main objectives of this study were to improve a four comb manual extractor by converting it into an electric one with a safety break unit that handles 8 combs at once in order to extract big amounts of honey in a short period of time. Some physical characteristics such as moisture content, density, and viscosity of honey collected form three kinds of plants (alfalfa, cotton and citrus) were considered in this study. The effect of wax type (artificial paraffin wax and natural beeswax) and combs thickness and mass on the extracted honey was also investigated in this study. The mean moisture contents, density and viscosity at $25{ }^{\circ} \mathrm{C}$ for honey collected form citrus, alfalfa and cotton were $(18.10,16.98$ and 14.74 $\%) ;\left(1.40,1.41,1.43 \mathrm{~g} / \mathrm{cm}^{3}\right)$ and $(48.10,69.03$ and 137.96 poises), respectively. The mean density of the artificial paraffin wax and natural beeswax were 0.91 and $0.98 \mathrm{~g} / \mathrm{cm}^{3}$ respectively. The mean thicknesses and mass for combs collected from (alfalfa, cotton and citrus) were (3.91, 3.79 and $3.57 \mathrm{~cm}$ ) and (1707.46, 1640.50 and $1156.50 \mathrm{~g}$ ), respectively. The extractor was constructed to operate manually and electrically, which can be installed and operated at home or at the farm where breeding of honey bees is possible. The evaluation included two operation modes (manual and electric); three ages of honeycombs (used for 1, 2 and 3 years); three extracting times (08.00 am, 11.00 am and $02.00 \mathrm{pm}) ;$ and five extraction speeds $[5.70,12.56,14.65,17.58$ and $21.98 \mathrm{~m} / \mathrm{s}]$.

\footnotetext{
${ }^{*}$ Researcher, Agric. Eng. Res. Institute, ARC.

${ }^{* *}$ Lec. Agric. Eng., Fac. Agric. Damietta Univ.
} 
It was observed that the maximum value of extracting efficiency was achieved with the electric extractor for, honeycombs used for 3 years, at $02.00 \mathrm{pm}$ and at an extraction speed of $21.98 \mathrm{~m} / \mathrm{s}$. The maximum value of extracting capacity was achieved with electric extractor for, honeycombs used for 2 years; at $02.00 \mathrm{pm}$ and at an extraction speed of $21.98 \mathrm{~m} / \mathrm{s}$. Minimum value of broken honeycombs was achieved with the electric extractor for the, honeycombs used for 3 years, if extracted at 08.00 am and at a speed of $12.56 \mathrm{~m} / \mathrm{s}$.

Keywords: development, evaluation, centrifugal, honey extractor, physical characteristics, honeycombs.

\section{INTRODUCTION}

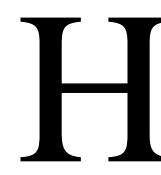
oney in this research referred to the honey produced by honey bees (Apis mellifera) that consider one of the best known nectar of blossoms or from the selection of living parts of plants or excretions of plant sucking insects on the living parts of plants, which honey bees collects, transformed and combine with specific substances of their own, store and leave in the honeycomb to ripen and mature (Breadbear, 2009). So it is the most important primary product of beekeeping both quantitatively and economically (Meda et al., 2005). Egypt production from natural honey in 2012 was estimated to be 5,700 metric tonnes. (Faostat, 2012) . Honey contains a wide range of sugars, depending on the nectar source and small amounts of other substances such as minerals, vitamins, proteins and some organic acids (Jasim et al., 2007). Honey is composed of simple sugars, mainly fructose, glucose, maltose and raffinose among others (Andrew et al., 2004).Essentially, glucose and fructose are its major constituents (Jeff, 2002; Nagai et al., 2002). Weaver and Weaver, (2000) reported that honey improves food assimilation and is to be used for chronic and infective intestinal problems such as constipation, duodenal ulcers and liver disturbance. Honey can be made dried or dehydrated by various industrial techniques by including inclusion in some recipes Sanford, (2000). Because of these benefits, honey extraction is very important. There is no available 
documented information or data on these important physical properties of Egyptian honey for purposes processing and storage.

In the designing of honey extraction and processing equipment, these properties play a major role. Many countries in the world such as Britain, Australia, New Zealand, Germany, Brazil, USA, Nepal and India have carried out extensive research on their honey regarding these parameters and as a result have managed to design and fabricate extraction and processing equipment as well as setting favorable conditions for its use (Crane, 1979; Ricciardelli, D and Albore, 1998; Terrab et al., 2004). Moisture content, (amount of water in $100 \mathrm{~g}$ honey) which is a parameter that is related to climatic conditions, season of the year and the degree of honey maturity (Terrab et al., 2004) is quantitatively the second most abundant component of honey apart from sugars. Its content is quite critical, for it affects honey storage (Nanda et al., 2003). The density of honey is an important physical property that influences stratification in honey. Honey density is slightly greater than that of water although it depends on the water content of honey (Nanda et al., 2003). Different types of honey may have different densities because of water content variation. Therefore, when honeys with different specific gravity are put together in storage tanks, they show distinct stratification. The less dense honey with high moisture content, settles above the denser drier honey. This prompts more thorough mixing during processing and packing to avoid such inconvenient separation. The extent of mixing and the ultimate moisture content of honey in the storage tanks will depend on the individual specific gravity of different types of honey (Moar, 1985). Viscosity is the property of a fluid that resists the force tending to cause fluid flow. It is one of the most important physical and sensory characteristics of honey, which affects the quality of the product and the design of honey processing equipment. It is crucial in all processengineering stages of production, starting from the extraction of honey from the combs, straining, mixing of different honey types, pumping, processing to packaging. Viscosity of many liquids, including honey is sensitive to temperature changes, decreasing when temperature increases. Liquids with this behavior are referred to as Newtonian liquids. From the literature, many honey varieties exhibit Newtonian flow behavior 
(Sopade et al., 2003; Mossel et al., 2000). When honey is freshly extracted from honey combs, it is a viscous liquid and its viscosity depends on a large variety of substances and therefore varies with its composition and particularly its water content (Bhandari et al., 1999). Viscosity is an important technical parameter during honey processing because it affects honey flow during extraction, pumping, settling, and filtration, mixing and boiling (White, 1975; Yanniotis et al., 2006). The viscosity increases with agitation or stirring and therefore during honey processing, this important property must be taken into considerations (FAO, 1996; Yanniotis et al., 2006).

The honey extracted with manual extractor is sticky and inefficient and time consuming. Series of extractor have been developed in advance countries e.g. United States, Germany, Australia, Italy and other (such extractors as the tangential, the radial, the automatic programmable and the electrical driven types (Sammataro and Alphonse, 1986). Beekeepers from developing countries such as Egypt will not be able to buy the types mentioned above because of their costs. Therefore, there is a need to develop the local manual tangential extractor, that is made from affordable materials.

\section{Therefore, the objectives of the present study were as follows:}

a) to investigate some physical properties of honey produced from different regions in Egypt.

b) to allow data for designing and fabrication of processing equipment for Egyptian honey.

c) to develop a small manual honey extractor that is affordable by beekeeper.

d) to study and recommend the best combination of operating parameters for the developed machine that maximize the extracting efficiency $\left(\eta_{\mathrm{e}}, \%\right)$ and extracting capacity $(\mathrm{Ec}, \mathrm{kg} / \mathrm{h}$.) and minimized the broken honeycombs, $\left(\mathrm{B}_{\mathrm{c}}, \%\right)$ and operation cost (conseguently reduce the production cost 


\section{MATERIALS AND METHODS}

\section{1- Materials:}

Bees from a private apiary at Meet-Salseel, EL- Dakahliyah, Egypt were used for nectar collection from three kinds of flowers (citrus, alfalfa and cotton). Some physical properties such as : moisture contents, density and viscosity were considered to develop and evaluate a manual tangential honey-extractor.

\section{1-1 Physical properties:}

\section{1-1-1 Moisture content (w, \%):}

A $20.0 \mathrm{~g}$ honey sample was put in a $50 \mathrm{ml}$ flask, closed tightly and then placed on water bath at $50{ }^{\circ} \mathrm{C}$ for dissolution of any sugar crystals. It was cooled to ambient temperature and a small amount (two to three drops) was put on the refractometer prism, spread evenly and refractive index determined after two minutes $(\boldsymbol{A O A C}, 1990)$. The values obtained used to determined moisture content (w, \%) using Wedmore Table of refractive index (Wedmore, 1955) based on the following equation:

$$
w=\frac{1.73190-\log (R \cdot I .-1)}{0.002243} \rightarrow(1)
$$

where: w : is the water content in $\mathrm{g}$ per $100 \mathrm{~g}$ of honey and R.I.: is the refractive index of honey.

\section{1-1-2 Density of honey $\left(\rho \mathrm{h}, \mathrm{g} / \mathrm{cm}^{3}\right)$ :}

The mass ( $M$, gram) of honey was determined (in gram) by using an electric digital balance with an accuracy of $0.0001 \mathrm{~g}$. The density $\left(\rho_{\mathrm{h}}\right.$, $\mathrm{g} / \mathrm{cm}^{3}$ ) of honey was determined by using a graduated flask with a known volume. It was filled with honey samples. Its volume was estimated by filling with water. The water was then weighed and the volume was calculated by using the following equation.

$$
V=\frac{M_{w}}{\rho_{w}} \quad \rightarrow(2)
$$

where $\mathbf{M}_{\mathbf{w}}$ is the mass of water in $\mathrm{g}$ and $\boldsymbol{\rho}_{\mathbf{w}}$ is the density of water, $\mathrm{g} / \mathrm{cm}^{3}$ The density of honey was calculated as the ratio of the mass and the volume of the container as follows: 


$$
\rho_{h}=\frac{m}{v}, g / \mathrm{cm}^{3} \rightarrow(3)
$$

where: $\boldsymbol{\rho} \mathbf{h}$ is the density of the honey, $\mathrm{g} / \mathrm{cm}^{3}, \mathbf{m}$ is the mass of honey in $\mathrm{g}$ and $\mathbf{v}$ is the volume of the container in $\mathrm{cm}^{3}$.

\section{1-1-3 The coefficient of viscosity ( $\eta$, poise):}

It was measured by dropping a ball bearings (with $1.0,1.5$ and $2.0 \mathrm{~cm}$ radii) into a jar of honey and timing the fall between two points. The velocity of balls was calculated by using the following equation.

$$
v=\frac{d}{t} \quad, \mathrm{~cm} / \mathrm{sec} \quad \rightarrow(4)
$$

where $\mathbf{v}$ is the velocity of every ball in $\mathrm{cm} / \mathrm{sec}$, $\mathbf{d}$ is the distance between two points in $\mathrm{cm}$ and $\mathbf{t}$ is the time of falling in sec.

$$
\eta_{n}=\frac{2 r^{2} g}{9 v}\left(\rho_{s}-\rho_{h}\right) \rightarrow(5)
$$

Where $\boldsymbol{\eta}_{\mathbf{n}}$ is the coefficient of viscosity for every ball (poise), $\boldsymbol{\rho}_{\mathbf{s}}$ is the ball density $\left(7.8 \mathrm{gm} / \mathrm{cm}^{3}\right)$, $\boldsymbol{\rho}_{\mathbf{h}}$ is the honey density and $\mathbf{g}$ is $980 \mathrm{~cm} / \mathrm{s}^{2}$.

By repeating the last steps with different ball diameters, we can determine the average value of coefficient of viscosity ( $\eta$, poise).

$$
\eta=\frac{\eta_{1}+\eta_{2}+\eta_{3}}{3} \rightarrow
$$

Where $\boldsymbol{\eta} \mathbf{1}, \boldsymbol{\eta} \mathbf{2}$ and $\boldsymbol{\eta} \mathbf{3}$ are the coefficients of viscosity (in poise) for balls 1,2 and 3 , respectively.

1-1-4 Density of beeswax ( $\rho$ bwax, $\left.g / \mathrm{cm}^{3}\right)$ and paraffin wax $\left(\rho\right.$ pwax, $\left.g / \mathrm{cm}^{3}\right)$ : To measure the density of beeswax $\left(\rho_{\text {bwax }}, g / \mathrm{cm}^{3}\right)$ and paraffin wax $\left(\rho_{\text {pwax }}\right.$, $\mathrm{g} / \mathrm{cm}^{3}$ ), the wax samples were sized into cubes with known dimensions and weighed by using an electric digital scale with an accuracy of $0.0001 \mathrm{~g}$.

\section{1-1-5 Thickness ( $T$, cm):}

To determine the average thickness $(T, \mathrm{~cm})$ of the combs, a sample of 100 randomly selected combs was used. The thickness was measured by caliper with an accuracy of $0.05 \mathrm{~mm}$.

\section{1-1-5 Weight of combs (M, gram):}

The load should balance by spreading the weight evenly around the reel so, a digital scale was used to determine the weight of combs samples ( $\mathrm{M}$, gram) with an accuracy of 0.01 gram. 


\section{1-2 Machine Description:}

Figures (1 and 2) illustrate the tangential extractors type (the combs sit tangent to the direction of the spinner's rotation) that is used in this study for extracting honey. It includes a central drive shaft carrying the assistant manual driving system on its top and it is provided with the electric driving system on its bottom. The cages can be turned, so we did not need to remove and replace the combs. Each frame was spun to extract honey from the outer side of the honeycomb and then it is turned to extract the rest of the honey from the other side. The whole mechanism was loaded on 4 legs and housed in a galvanized cylindrical container for honey collection and evacuation. During this process, the extractor should be kept in a horizontal position.

This machine consists of an extraction unit; an electric power drive unit and its transmission system; an assistant manual drive unit and a brake unit.

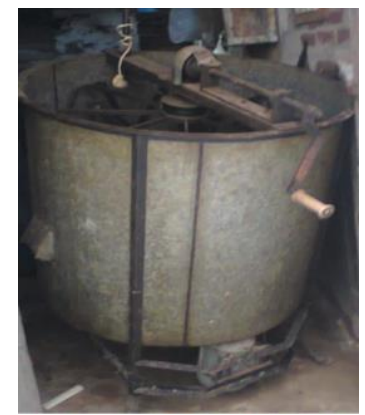

\section{Figure 1: The honey extractor}

The machine has a diameter of $100 \mathrm{~cm}$ and a height of $147 \mathrm{~cm}$, and it weights $245 \mathrm{~kg}$. The extraction unit can handle 8 baskets $[40 \mathrm{~cm}$ x $20 \mathrm{~cm}$ x $5.5 \mathrm{~cm}$, each] at once. It consisted of a central axle drive shaft, $15 \mathrm{~mm}$, held by two bearings. A ball bearing was fitted at the top of the basket holder and the axle rod was passes through it. A bush bearing was fixed to the bottom of the cylindrical container. The upper surface of the bush has a socket and steel balls. The bush was raised and a seal was used on the top of the bush to avoid mixing of grease or worn out parts of steel with the honey. There were 8 bars at the upper and lower sides of the shaft for the 8 hanging wire baskets. The baskets were arranged tangent to the circular shape against the outer side of the cylindrical container. 
The baskets, which hold the combs for extracting, were very simple. They have rectangular tops and bottoms. The clearance between the baskets and the cylindrical container was $50 \mathrm{~mm}$. The aluminum wire-mesh should be only on the side walls to allow the honey to pass through them. Leaving the bottoms open would provide them enough structural support to securely hold the combs upright and prevent them from falling into the bottom of the tank. All baskets can be swiveled on their axis without removing them from the extractor. There was a wrapping bungee cord around the tank to force baskets back into a circular shape. The height of the cylindrical container was $93 \mathrm{~cm}$. The cylindrical container has a conical bottom. The outlet was provided with a honey gate (knife type) valve ( $25 \mathrm{~mm}$ in diameter and, $50 \mathrm{~mm}$ in length). It is fixed in a position that enables the cylindrical container to be completely emptied with minimum tilting.
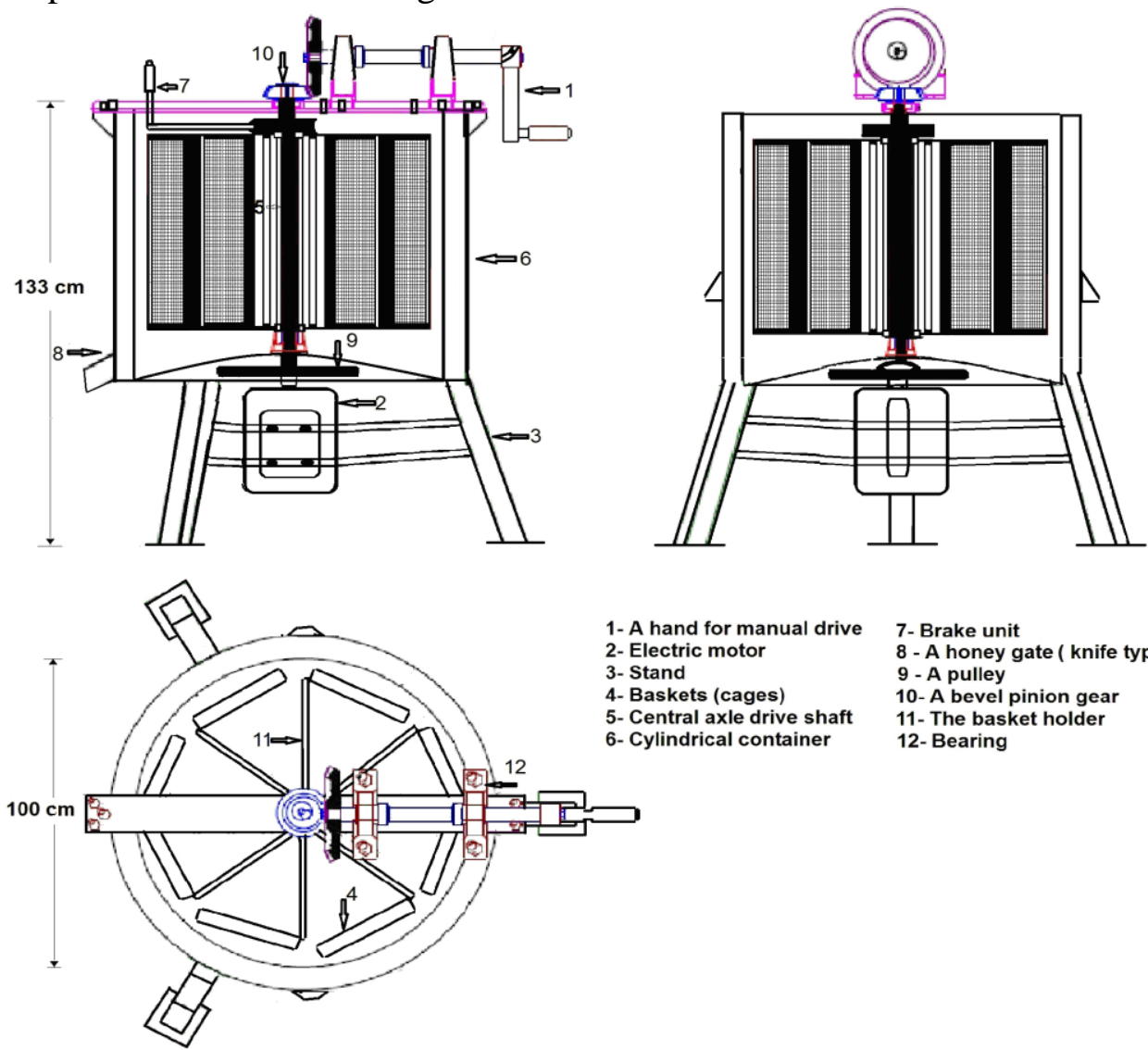

7- Brake unit 8 - A honey gate ( knife type) 9 - A pulley 10-A bevel pinion gear 11- The basket holder 12- Bearing

Figure 2: Elevation, side view and top view of the developed extractor. 
An electric motor of $0.75 \mathrm{~kW}(1 \mathrm{hp}), 50 \mathrm{HZ}$ and $380 \mathrm{~V}$ at rotating speed of $1400 \mathrm{rpm}(4.4 \mathrm{~m} / \mathrm{s})$, three phase was placed under the extractor. The power is transmitted from the motor directly to a main drive shaft by means of cast iron pulleys and V-belt. The electrical motor can be moved on its base to allow adjusting the belt tension. So as the motor spins, the belt will rotate and spins the frame holder.

The electric motor has a pulley, $6 \mathrm{~cm}$ diameter O.D., to give the required r.p.m. of the main drive shaft. The power is transmitted from the electric motor to pulleys [20, 25, 30 and $35 \mathrm{~cm}$ (O.D)] fitted on the main shaft. It changes the roller speed to 240, 280, 336 and 418 r.p.m $(12.56,14.65,17.58$ and 21.98 $\mathrm{m} / \mathrm{s}$ ), respectively.

The assistant manual system consists of a handle made from two pieces. The first piece of the handle should pass through the holes provided in the handle support, which in turn is fixed on a steel strip (6 mm thick and $40 \mathrm{~mm}$ wide) running across the cylindrical container. This mild steel strip carrying the handle support should be supported by two steel brackets riveted to the cylindrical container. One end of the first piece of the handle have beveled gear, which engages with a beveled pinion supported on the top of the central shaft. The gear ratio was 1:5. The other end of the first piece of the handle is fixed to one end of the second piece of the handle. A wooden grip is provided for the other end of the second piece of handle. The handle operated sideways.

The brake unit consists of an arm assembled in a vertical position and fixed in the steel strip in one point. At the lower end of the arm there was a short steel rod ended with a half circle ring coated with rubber. When the arm attracted back the half circle ring fractioned with a pulley assembled under the beveled pinion and stopped the extractor.

\section{1-3 Studied factors:}

\section{1-3-1 Variable factors:}

\section{1-3-1-1 Extractor type:}

Two types of extractors were used. They were manual and electric named $\mathrm{E}_{1}$ and $\mathrm{E}_{2}$, respectively.

\section{1-3-1-2 The age of honeycombs:}

Three ages of honeycombs were used. They were used for 1, 2 and 3 years named $\mathrm{c}_{1}, \mathrm{c}_{2}$ and $\mathrm{c}_{3}$, respectively. 


\section{1-3-1-3 Extraction time:}

Three extracting times were used. They were $08.00 \mathrm{am}, 11.00 \mathrm{am}$ and 02.00 pm, which were named $T_{1}, T_{2}$ and $T_{3}$, respectively.

\section{1-3-1-4 Extraction speeds:}

Five levels of speeds were measured. They were 5.7, 12.56, 14.65, 17.58 and $21.98 \mathrm{~m} / \mathrm{s}$ named $\mathrm{S}_{1}, \mathrm{~S}_{2}, \mathrm{~S}_{3}, \mathrm{~S}_{4}$ and $\mathrm{S}_{5}$, respectively.

\section{1-3-2 Relatively fixed factors:}

1- Power: - An electric motor of $0.75 \mathrm{~kW}(1 \mathrm{hp})$.

2- Extracting time: - 3 min.

3- Clearance between the frame and the basket about $0.8 \mathrm{~cm}$ from all sides.

4- Honey type: - collected from alfalfa.

\section{2- Methods:}

The experimental procedure that was carried out on the developed machine was extracting efficiency, honeycombs breakage and extracting capacity.

\section{2-1 Machine unit measurements:}

For preparing the machine for operation the clearances should be sufficient to minimize honeycombs damage and facilitate frame loading. Four clearance $(2.5,1.0,0.8$ and $0.5 \mathrm{~cm})$ were studied. Initially and the results indicated that when the clearance was too high, the honeycombs was damaged, and when it was too small, the loading of combs was very difficult, so the optimum clearance with minimum damage and easy loading was $0.8 \mathrm{~cm}$.

The electric motor has to be moved to be able to match the different pulley diameters $(20,25,30$ and $35 \mathrm{~cm})$ on the main shaft and consequently change the drum speed (240, 280, 363 and 418 r.p.m) respectively.

The speeds of rotation of the main axial shafts were measured by laser optical tachometer device with range of 1:99.999 $\mathrm{rev} / \mathrm{min}$ and accuracy of $+(0.05 \%+$ 1 digits).

\section{2-2 Extracting processes:-}

First the honeycombs areextracted from the beehives. The next step is to uncap the honey combs. The wax cappings are sliced off by a sharp long knife or special knives heated by steam or electricity or by capping scratchers (Jeff Rounce, 2002). After the honey is uncapped, it is put into honey extractor that should be kept in horizontal position during process. The load should be balanced by spreading the weight evenly around the reel. If it is unbalanced, the 
extractor will vibrate too much when the reel rotates and the honey may not be extracted completely. Each frame was handled four times, load, turn, turn, unload and the machine has to be started and stopped four times. The honey is extracted by spinning it out of the honeycombs to the cylindrical container wall and then it flows by gravity into the lower. The frame was only handled twice as it should be emptied on one side then turned and emptied on the other side. When the extraction is complete, we should turn the switch "off". The basket keeps rotating by force of inertia, so should not be braked suddenly. The honey was moved into the base of the extractor. Once the level of the honey reaches the level of the spinner, we must stop and open the gate. When using the extractor, we placed a bucket under the extractor's open honey gate to continually drain the honey. The wax is separated from the honey by filtering through a sieve or by pressing. At the end of process, the combs are removed and put back into the bee hives so that the bees can fill them with honey in the next season.

The experiments were carried out on one species of honey-bee (Apis mellifera carnica). The tests were carried out at the periods from 20-30 April , 1-10 June and 1-10 September to study the effect of the modified extracting machine upon the extracting efficiency, honeycombs damage and extracting capacity (productivity) as affected by extractor types (manual and electric) named $\mathrm{E}_{1}$ and $\mathrm{E}_{2}$, respectively; honeycombs conditions (used for 1, 2 and 3 years), named $\mathrm{C}_{1}$, $\mathrm{C}_{2}$ and $\mathrm{C}_{3}$, respectively; extracting times (08.00 am, 11.00 am and $02.00 \mathrm{pm}$ ), named $\mathrm{T}_{1}, \mathrm{~T}_{2}$ and $\mathrm{T}_{3}$, respectively and extraction speeds (5.7, 12.56, 14.65, 17.58 and $21.98 \mathrm{~m} / \mathrm{s}$ ), called $S_{1}, S_{2}, S_{3}, S_{4}$, and $S_{5}$, respectively. Three readings (replicates) were taken and all values were recorded.

\section{2-3 Measurements and calculations:-}

To determine the optimum conditions for the honey extracting under study, the following calibration criteria were studied: -

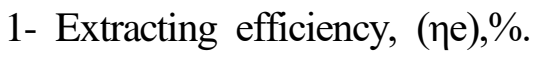

2- Broken honeycombs, (Bc) ,\%.

3- Extracting capacity $(\mathrm{Ec}), \mathrm{kg} / \mathrm{h}$.

The extracting efficiency ( $\eta$ e), \% was determined according the following relation:-

$$
\eta_{e}=\frac{W_{\text {out }}}{W_{\max }} \times 100 \rightarrow(7)
$$

Where:- 
$\mathrm{W}_{\text {out }}=$ Weight of extracted honey, $\mathrm{kg}$.

$\mathrm{W}_{\text {max. }}=$ Maximum weight of extracted honey, $\mathrm{kg}$.

The broken honeycombs $\left(\mathrm{B}_{\mathrm{c}}\right)$, \% was determined according to the following relation:-

$$
\mathrm{B}_{c}=\frac{N_{b}}{N_{\text {in }}} \times 100 \rightarrow(8)
$$

Where:-

$\mathrm{N}_{\mathrm{b}}=$ Number of broken combs.

$\mathrm{N}_{\text {in }}=$ Number of fed combs.

The productivity of the machine was determined with the help of a digital stopwatch of 0.1-sec. accuracy and an electrical scale of $(0.01 \mathrm{~g})$ accuracy. Machine productivity was calculated as follows:-

$$
P=\frac{W_{\text {out }}}{t}, \mathrm{~kg} / \mathrm{h}
$$

Where:

$\mathrm{t}=$ time of test duration (hr.).

\section{2-4 Statistical analysis:-}

All obtained data was presented in figures and was analyzed statistically by using a computer program (Minitab Release 15) for estimating the probability at levels 1 and 5\%. The graphs were drawn using the Microsoft excel window 2007.

\section{RESULTS AND DISCUSSION}

Data illustrated in figures. (3 and 4) show the comparative magnitude of mean percentage values of some physical characteristics [moisture content $(w, \%)$, density $\left(\rho_{h}, g / c m 3\right)$ and the coefficient of viscosity $(\eta$, poise)] of honey collected form three kinds of plants (alfalfa, cotton and citrus $)$. The density of artificial paraffin $\operatorname{wax}\left(\rho_{\mathrm{pwax}}, \mathrm{g} / \mathrm{cm}^{3}\right)$ and natural beeswax $\left(\rho_{b w a x}, \mathrm{~g}_{\mathrm{cm}}{ }^{3}\right)$. Combs thickness $(\mathrm{T}, \mathrm{cm})$ and mass $(\mathrm{M}$, gram $)$ for honey collected form (alfalfa, cotton and citrus) were.

\section{Considerations due to the results on studied physical properties:}

The refractive index was measured for the honey samples and the values obtained were used to determined moisture content (using Wedmore 
table of refractive index). Wedmore table uses the relationship given in equation 1 (Wedmore, 1955) of moisture content and refractive index. The results of the refractive index of honey collected form citrus, alfalfa and cotton were $1.49125 \pm 0.00095$ (varying from 1.490 to 1.493); $1.49408 \pm 0.00087$ (varying from 1.4930 to 1.4961 ); and $1.49981 \pm$ 0.000988 (varying from 1.4987 to 1.5018 ), respectively. The mean moisture contents, $\%$ at $25{ }^{\circ} \mathrm{C}$ for honey collected form citrus, alfalfa and cotton were $18.1 \pm 0.38 \%$ (varying from 17.4 - 18.6\%); $16.98 \pm 0.33 \%$ (varying from $16.2-17.4 \%$ ); and $14.74 \pm 0.42 \%$ (varying from 14.0 $15.2 \%)$, respectively. The lower moisture content was achieved with cotton honey, due to the low humidity during September month. It was remarked that the moisture content $(\mathrm{w}), \%$, decreased with honey source, according to the following descending order [citrus <alfalfa <cotton].

The mean density at $25{ }^{\circ} \mathrm{C}$ for honey collected form citrus, alfalfa and cotton were $1.4 \pm 0.006 \mathrm{~g} / \mathrm{cm}^{3}$ (varying from $1.39-1.41 \mathrm{~g} / \mathrm{cm}^{3}$ ); $1.41 \pm$ $0.012 \mathrm{~g} / \mathrm{cm}^{3}$ (varying from $1.39-1.42 \mathrm{~g} / \mathrm{cm}^{3}$ ); and $1.43 \pm 0.012 \mathrm{~g} / \mathrm{cm}^{3}$ (varying from $\left.1.41-1.45 \mathrm{~g} / \mathrm{cm}^{3}\right)$, respectively. It was remarked that $\left(\rho_{\mathrm{h}}\right)$, $\mathrm{g} / \mathrm{cm}^{3}$ increases as the moisture content decreases, according to the following descending order [citrus <alfalfa <cotton].

The mean coefficient of viscosity at $25{ }^{\circ} \mathrm{C}$ for honey collected form citrus, alfalfa and cotton were $48.1 \pm 0.397$ poises (varying from 47.548.9 poises); $69.03 \pm 0.727$ poises (varying from $68-70$ poises); and $137.96 \pm 0.450$ poises (varying from $137-138.7$ poises, respectively. It was noticed that $\eta$, poises, increased as the moisture content decreased, according to the following descending order [citrus < alfalfa < cotton].
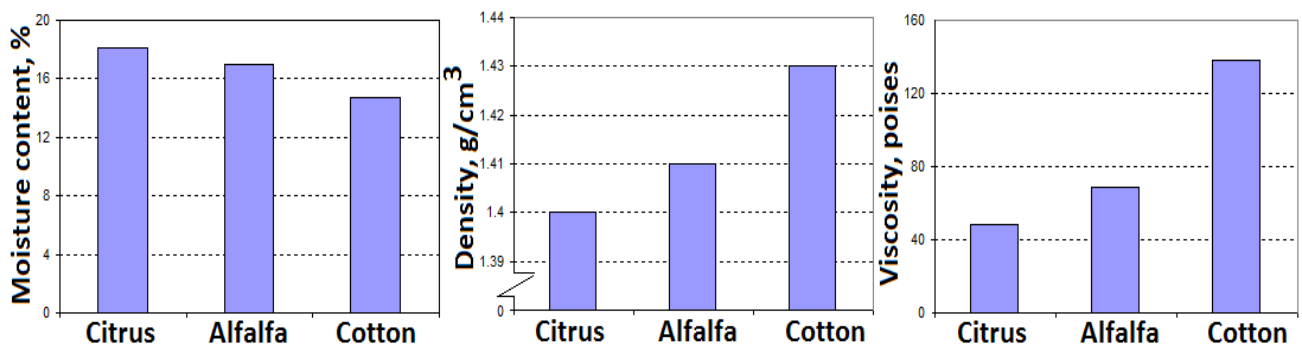

Figure 3: Effect of honey source on moisture content, g/100g; density, $\mathrm{g} / \mathrm{cm}^{3}$; and the coefficient of viscosity, poise. 
The mean density of artificial paraffin wax and natural beeswax (figure 4) were $0.91 \pm 0.031 \mathrm{~g} / \mathrm{cm}^{3}$ varying from $0.85-0.97 \mathrm{~g} / \mathrm{cm}^{3}$ and $0.98 \pm$ $0.013 \mathrm{~g} / \mathrm{cm}^{3}$ varying from $0.955-0.998 \mathrm{~g} / \mathrm{cm}^{3}$ respectively. It was remarked that $\left(\rho_{\mathrm{w}}\right), \mathrm{g} / \mathrm{cm}^{3}$ increased with wax source, according to the following descending order [artificial paraffin wax < natural beeswax].

The mean thickness (figure 4) for combs of honey collected form citrus, alfalfa and cotton were $3.57 \pm 0.82 \mathrm{~cm}$ varying from $2.3-4.7 \mathrm{~cm} ; 3.91$ $\pm 1.07 \mathrm{~cm}$ varying from $2.7-5.4 \mathrm{~cm}$; and $3.79 \pm 0.86 \mathrm{~cm}$ varying from $2.5-5.1 \mathrm{~cm}$ respectively. The mean mass (figure 4) for combs of honey collected form citrus, alfalfa and cotton were $1156.5 \pm 398.93$ gram (varying from 491-1789 gram); $1707.46 \pm 499.59$ gram (varying from 934-2606 g); and $1640.5 \pm 563.24$ gram (varying from 673-2463 g), respectively. Higher thicknesses and masses were achieved with alfalfa honey, due to the moderate weather during the period from 25 May to 10 June and the big flowering area of Alfalfa. It was noticed that $(\mathrm{T}), \mathrm{cm}$, and $(\mathrm{M}), \mathrm{g}$, increased with honey source, according to the following descending order [citrus $<$ cotton $<$ alfalfa].
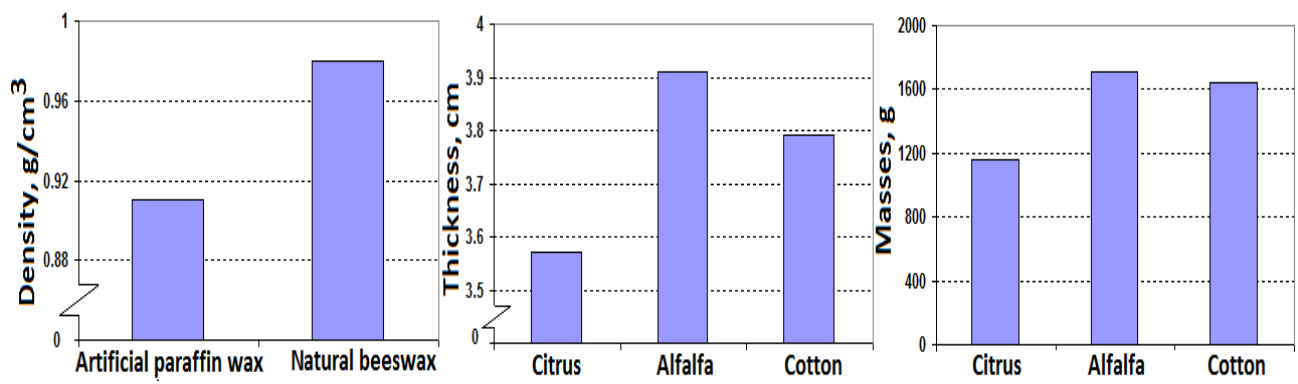

Figure 4: Effect of wax types on density, $\mathrm{g} / \mathrm{cm}^{3}$; and honey types on thickness, cm and masses, gram of combs.

Data illustrated in figures (5 to 7 ) show the comparative magnitude of mean percentage values of extracting efficiency ( $\eta$ e., \%), broken honeycombs, $(\mathrm{Bc}, \%)$ and extracting capacity $(\mathrm{Ec}, \mathrm{kg} / \mathrm{h}$.)

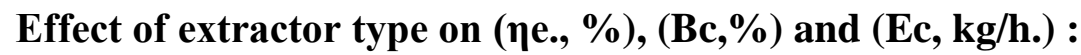

The ( equation7, 8 and 9 respectively. Figure 5 showed the effect of extractor 


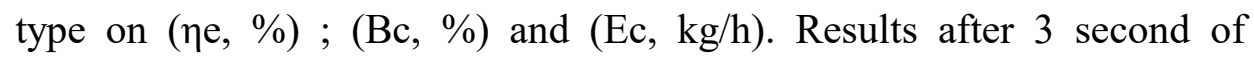
extracting honey (Alfalfa) show that the mean ( $\eta \mathrm{e}, \%$ ) increases from $54.54 \%$ with manual extractor to $88.24 \%$ with electric one due to the high steady velocity. The less mean (Bc, \%) was $1.85 \%$ with electric due to the less sudden motion with the electric driven. The maximum mean $(\mathrm{Ec}, \mathrm{kg} / \mathrm{h}$ ) was $92.72 \mathrm{~kg} / \mathrm{h}$, which was achieved with the electric extractor due to the higher centrifugal force that extracted a maximum

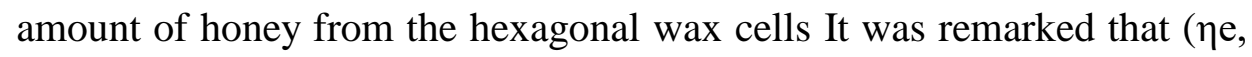
$\%$, ) and $(\mathrm{Ec}, \mathrm{kg} / \mathrm{h}$,) increased and $(\mathrm{Bc}, \%)$ decreased ; with extractor type, according to the following descending order [manual < electric].
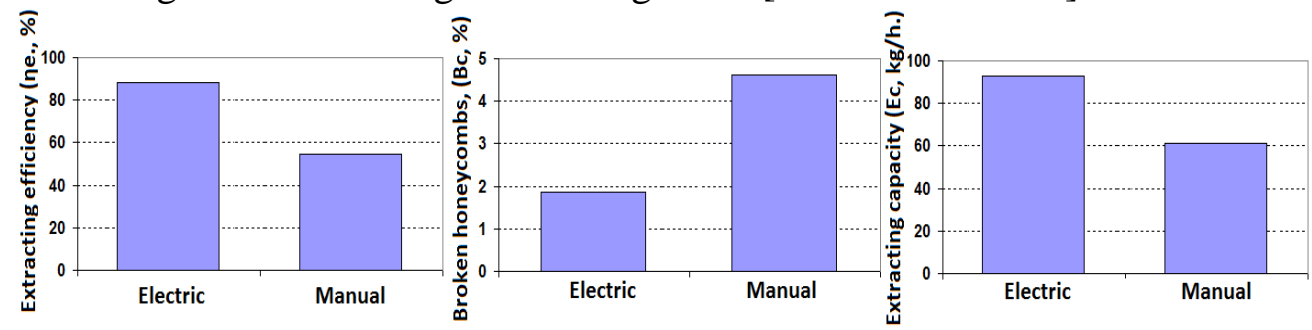

Figure 5: Effect of extractor type on extracting efficiency ( broken honeycombs, (Bc, \%) and extracting capacity (Ec, kg/h.)

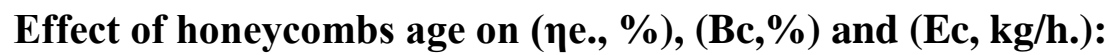

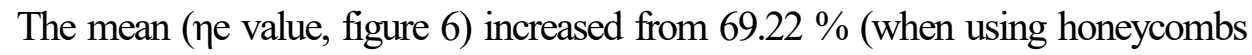
for 1 year) to $74.03 \%$ (when using honeycombs for 3 years) because bees make hexagonal wax cell walls strong during every process of alienation so a less deterioration occurred while scraping with the serrated sharp knife in untapped process. The mean $(\mathrm{Ec}, \mathrm{kg} / \mathrm{h})$ decreases from $82.46 \mathrm{~kg} / \mathrm{h}$ when using honeycombs for 2 year to $74.95 \mathrm{~kg} / \mathrm{h}$ when using honeycombs for 3 years, due to the smaller size of hexagonal cells from year to year that produce small and weak workers. The lower mean $(\mathrm{Bc}=1.99 \%)$ was achieved when using honeycombs used for 3 year, due to the its hardness. It was noticed that ( $\eta \mathrm{e}, \%)$ and $(\mathrm{Bc}, \%)$ decreased; with honeycombs age, according to the following descending order $[1$ year $<2$ year $<3$ year] but the $(\mathrm{Ec}, \mathrm{kg} / \mathrm{h})$ increased with honeycombs age, according to the following descending order $[1$ year $<3$ year $<2$ year]. 


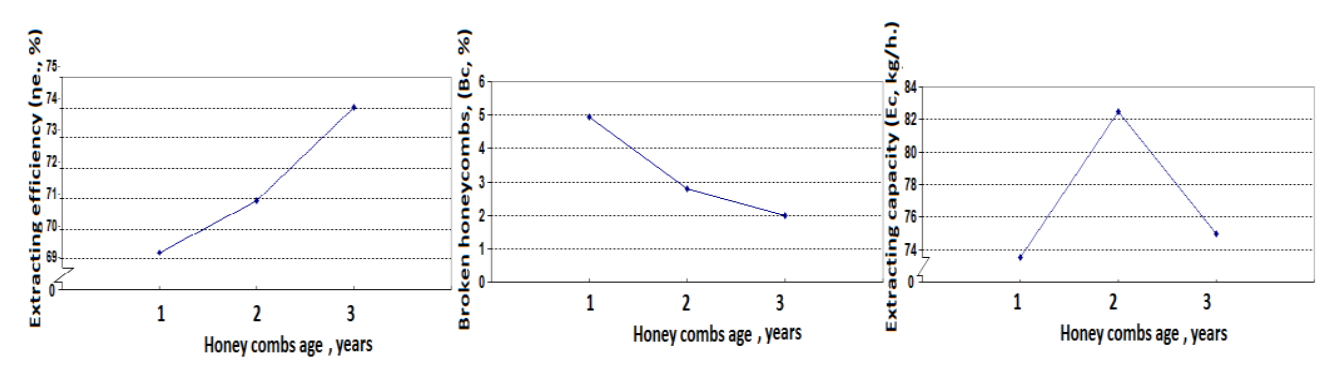

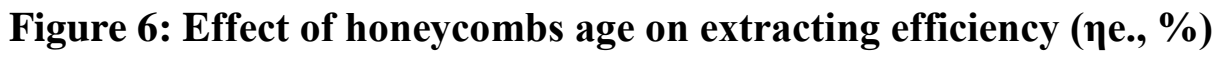
$\%)$, broken honeycombs, (Bc,\%) and extracting capacity (Ec, kg/h.)

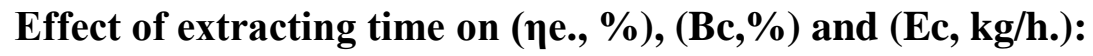

The mean $\eta \mathrm{e}, \%$, increased from $64.14 \%$ in the morning $(8.00 \mathrm{am})$ to $78.36 \%$ in the afternoon $(2.00 \mathrm{pm})$, due to the less viscosity of honey in the afternoon $(2.00 \mathrm{pm})$, figure 7 . The $\mathrm{Bc}, \%$, increased also by increasing temperature in the afternoon. The minimum mean $(\mathrm{Bc}, \%$, was about $1.95 \%$ in the morning $(8.00 \mathrm{am})$. Generally Bc, $\%$, increased due to wax melting at the higher temperature. The mean $\mathrm{Ec}, \mathrm{kg} / \mathrm{h}$., increased from $64.08 \mathrm{~kg} / \mathrm{h}$. (at $8.00 \mathrm{am}$ ) to $90.33 \mathrm{~kg} / \mathrm{h}$. (at $2.00 \mathrm{pm}$ ), due to the higher ambient temperature and the less viscosity of the honey in the afternoon. It was noticed that $\eta \mathrm{e}(\%), \mathrm{Bc}(\%)$ and $\mathrm{Ec}(\mathrm{kg} / \mathrm{h})$ increased with increasing the extraction time of day, according to the following descending order $8.00 \mathrm{am}<11.00 \mathrm{am}<2.00 \mathrm{pm}$.

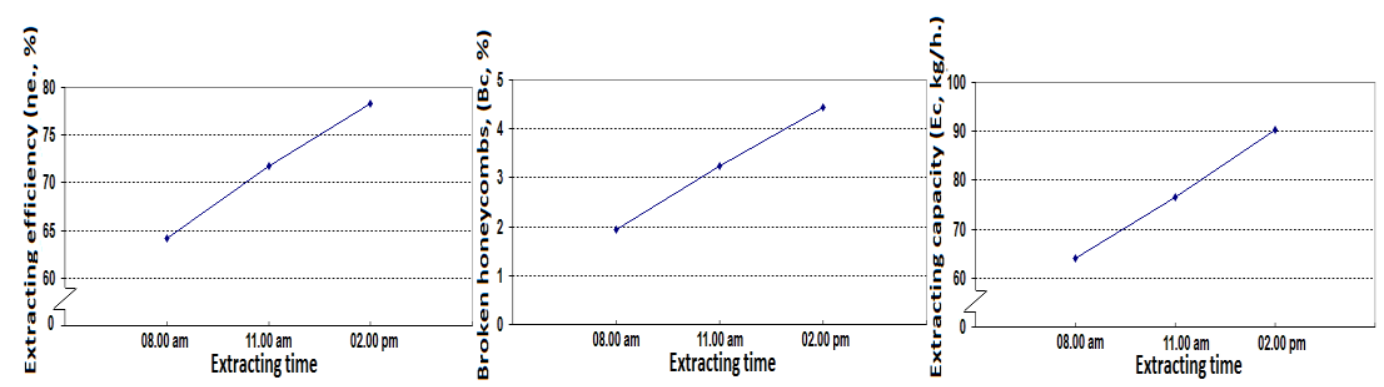

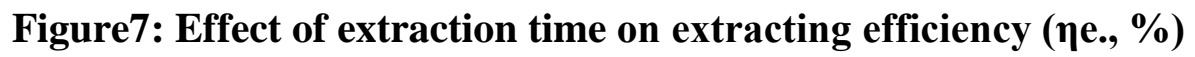
$\%)$, broken honeycombs, (Bc,\%) and extracting capacity (Ec, kg/h.)

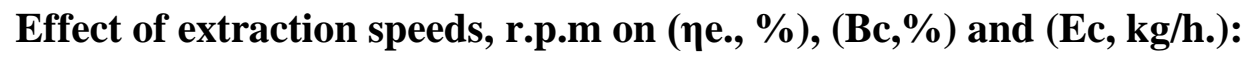
When increasing the electric extractor speeds from 5.7 to $21.98 \mathrm{~m} / \mathrm{s}$, the mean ne (\%) increased from 54.54 to $96.3 \%$ due to the increase in Centrifugal force (figure 8 ). The highest mean percentage of $\mathrm{Bc}(\%)$ was 
$4.63 \%$ at $5.7 \mathrm{~m} / \mathrm{s}$, due to the excessive vibration in the extracting unit with the manual extractor. The mean percentage of $\mathrm{Bc}(\%)$ was decreased to $0.81 \%$ at $12.56 \mathrm{~m} / \mathrm{s}$ with the electric extractor and started to increase by increasing extraction speed from 12.56 to $21.98 \mathrm{~m} / \mathrm{s}$. The maximum mean Ec $(\mathrm{kg} / \mathrm{h})$ was $102.56 \mathrm{~kg} / \mathrm{h}$, which was achieved at $21.98 \mathrm{~m} / \mathrm{s}$ due to the high centrifugal force that resulted in extracting all the honey located in hexagonal cells. It was noticed that $\eta \mathrm{e}(\%), \mathrm{Ec}(\mathrm{kg} / \mathrm{h})$ increased with the extractor speeds in descending order $(\mathrm{S} 1<\mathrm{S} 2<\mathrm{S} 3<\mathrm{S} 4<\mathrm{S} 5)$. However, the $\mathrm{Bc}(\%)$ decreased with extractor speeds, according to the following descending order $(\mathrm{S} 1<\mathrm{S} 5<\mathrm{S} 4<\mathrm{S} 3<\mathrm{S} 2)$.

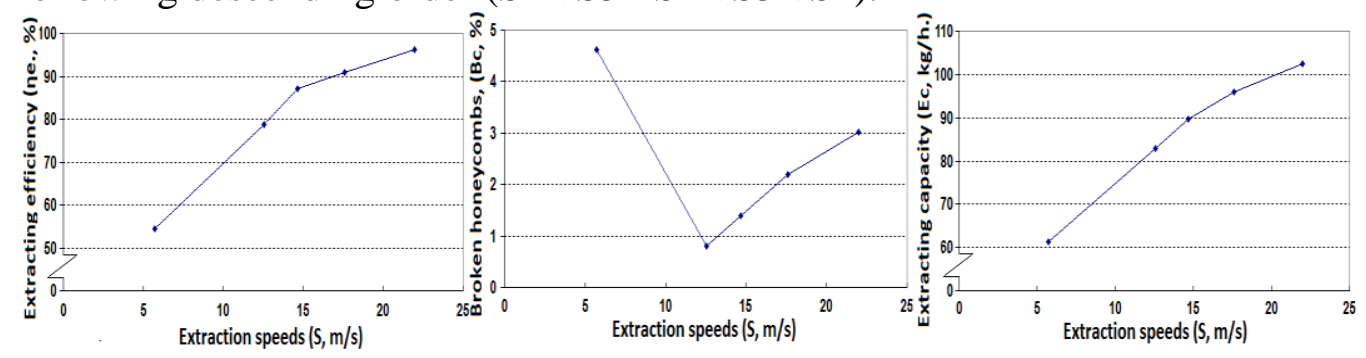

Figure 8: Effect of extraction speeds, $\mathrm{m} / \mathrm{s}$ on extracting efficiency

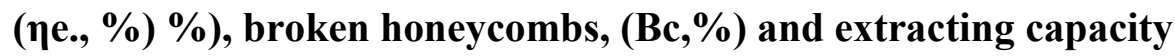
(Ec, kg/h.)

Table 1: ANOVA Analysis

\begin{tabular}{|l|c|c|c|}
\hline \multirow{2}{*}{ Changeable factor } & \multicolumn{3}{|c|}{ Measurements } \\
\cline { 2 - 4 } & $\begin{array}{c}\text { The extracting } \\
\text { efficiency }(\boldsymbol{\eta} \mathbf{e}), \boldsymbol{\%}\end{array}$ & $\begin{array}{c}\text { The broken honeycombs } \\
\mathbf{( B c )}, \%\end{array}$ & $\begin{array}{c}\text { The extracting } \\
\text { capacity (Ec), } \\
\mathbf{k g} / \mathbf{h} .\end{array}$ \\
\hline $\begin{array}{l}\text { The age of honeycombs, } \\
\text { (C) }\end{array}$ & $\mathrm{ns}$ & $* *$ & $\mathrm{~ns}$ \\
\hline Extraction time, (T) & $* *$ & $* *$ & $* *$ \\
\hline Extraction speeds, (S) & $* *$ & $\mathrm{~ns}$ & $* *$ \\
\hline $\mathbf{C}$ T and S & $* *$ & $* *$ & $* *$ \\
\hline $\mathbf{C}$ and T & $*$ & $* *$ & $* *$ \\
\hline T and S & $* *$ & $* *$ & $* *$ \\
\hline C and S & $* *$ & $* *$ & $* *$ \\
\hline
\end{tabular}

**, highly significant at $1 \%$ level; *, significant at $5 \%$ level; ns, non significant 
PROCESS ENGINEERING

\section{CONCLUSIONS}

The honey collected form cotton has the lowest percentage of moisture content; and the highest density and viscosity. The natural beeswax has the highest density. The highest yield was for honey collected form alfalfa. It was observed that the maximum values of extracting efficiency and extracting capacity were achieved with electric extractor; honeycombs used for 3 years; in the afternoon $02.00 \mathrm{pm}$ or in a hot room to lower the viscosity of the honey and extraction speed $21.98 \mathrm{~m} / \mathrm{s}$. The maximum values of extracting capacity were achieved with electric extractor; honeycombs used for 2 years; in the afternoon $02.00 \mathrm{pm}$ and extraction speed $21.98 \mathrm{~m} / \mathrm{s}$. Minimum value of broken honeycombs was achieved with electric extractor; honeycombs used for 3 years; at 08.00 am and extraction speed $12.56 \mathrm{~m} / \mathrm{s}$.

\section{REFERENCES}

Adebiyi, F.M.; Akpan, I.; Obiajunwa, E.I. and Olaniyi, H.B. (2004). Chemical/physical characterisation of Nigerian honey Pakstan Journal of Nutrition 3(5), 278-281.

Andrew, B.; Benard, E.; Nicholas, B.; Siphuel, A. and Nicholas, T. (2004). Quality evaluation of honey harvested from selected areas of Tanzania with special emphasis on hydroxymethyl furfural (HMF) levels. Journal of Plant Foods for Human Nutrition 15, 7595.

AOAC, (1990). Official methods of analysis, Acidity of Honey pp 9621033.

Bhandari, B.; Deearcy, B. and Chow, S. (1999). Rheology of selected Australian honeys. Journal of Food Engineering 41, 65-68.

Bogdanov S, Martin P, Lüllmann C (1997). Harmonised methods of the European Honey Commission. Apidologie, Extra issue pp. 1-59.

Breadbear N (2009). Bees and their role in forest livelihoods: A guide to the services provided by bees and the sustainable harvesting, processing and marketing of their products. Non Wood Forest Products 19. Food Agric. Organ. United Nations. Rome, p. 204. 
PROCESS ENGINEERING

Codex Alimentarius Commission (2001). Rapport de la 7e session du comité sur les sucres. Programme mixte FAO/OMS sur les norms alimentaires, p. 31.

Crane, E. (1979). Honey: A comprehensive survey. Henemann, London UK. pp 25-125.

David Cramp , 2008. A PRACTICAL MANUAL OF BEEKEEPING. British Library Cataloguing in Publication Data. First published in electronic form 2008.

FAO, (1996). Value added products from beekeeping. FAO Agricultural Services Bulletin. Rome, Italy: FAO. No. 120 (2), 20-29, 46-55.

FAO, (2004). Agricultural Services Bulletin, No. 124 (2), 22-25, 26-28.

International Honey Commission, (2002). Honey quality, methods of analysis and international regulatory standards. pp 2-35.

Faostat.

FAO.

Org,

(2012).http://faostat.fao.org/site/569/DesktopDefault.aspx?

PageID $=569 \#$ ancor Internet research in 01/03/2014.

Jasim, A.; Prabhu, S.T.; Raghavan, G.S.V.;and Ngadi, M. (2007). Physico-chemical, rheological, calorimetric and dielectric behavior of selected Indian honey. Journal of Food Engineering 79, 12071213.

Jeff R. (2002). "Honey from source to sale \& Show - bench," (Northen Bee Books) pp 10-79.

Meda, A., Charles E.L., Marco, R., Jeanne, M., Odile G.N. (2005), Determination of the total phenolic, flavonoid and proline contents in Burkina Fasan honey, as well as their radical scavenging activity. Food Chemistry 91, $571-577$.

Minitab Reference Manuel (release 15), Minitab Inc. State University Michigan. 
Moar, N. T. (1985). Analysis of New Zealand honey. New Zealand Journal of Agricultural Research 28, 39-70.

Mossel B; Bandari B; DeArcy B. and Caffin N. (2000). Use of an Arrhenius model to predict rheological behaviour in some Australian honeys, pp 545-552.

Nagai, T; Inoue, R; Inoue, H. and Suzuki, N. (2002). Scavenging capacities of pollen extracts from Cistus ladaniferus on autoxidation, superoxide radicals, hydroxyl radicals and DPPH radicals. Nutrition Research 22, 519-526.

Nanda, V.; Sarkar, B.; Sharma, H. and Bawa, A. (2003). Physicochemical properties and estimation of mineral content in honey produced from different plants in Northern India. Journal of Food Composition and Analysis 16, 613-619.

Ouchemoukh, S; Hayette, L. and Paul, S. (2007). Physicochemical characteristics and pollen spectrum of some Algerian honeys. Journal of Food Control 18, 52-58.

Pridal, A. and Vorlova, L. (2002). Honey and its physical parameters, Czech. Journal of Animal Science 47(10), 439-444.

Ricciardelli, D and Albore, G. (1998). Mediterranean Melissopalynology. Perugia: Institute of Agriculture Entomology, University of Perugia, pp $32-43$.

Smmataro, D. and Alphonse, A., 1986. The Beekeepers Handbook, New York, Macmillian.

Sanford, M. T., 2000. Working smarter, not harder: Apicultural productivity in the 21st century. Apis Newsletter; 18(10).

Sato, T. and Mayata, G. (2000). The nutraceutical benefit, part II: Honey, Nutrition 16, 468-469.

Sopade, P.; Halley, P.; Bhandari, B.; D Arcy, B.; Doebler, C. and Caffin, N. (2003). Application of the Williams-Landel-Ferry model to the 
viscosity-tempareture relationship of Australian honeys. Journal of Food Engineering 56, 67-75.

Terrab, A.; Angeles, F; Recamales, D.H.; Francisco, S and Heredia, J. (2004). Characterisation of Spanish thyme honeys by their physicochemical characteristics and mineral contents. Journal of Food Chemistry 88,537-542.

Terrab, A.; Diez ,M.J. and Heredia, F.J. (2002). Characterization of Moroccan unifloral honeys by their physicochemical characteristics. Journal of Food chemistry 79, 373-379.

Weaver, M. and Weaver B., 2000. Seaver's Delaware pollination business. Have bees will travel, American Bee Journal, 139(7).

Wedmore, E.B. (1955). The accurate determination of the water content of honeys bee World 36, 197-206.

White, J.W. (1975). Honey. The hive and the honeybee. (Ed Grout R.A) Hamiliton Illinois, pp. 625-646.

Yanniotis, S.; Skaltsi, S. and Karaburnioti, S. (2006). Effect of moisture content on the viscosity of honey at different temperatures. Journal of Food Engineering 72, 372-377.

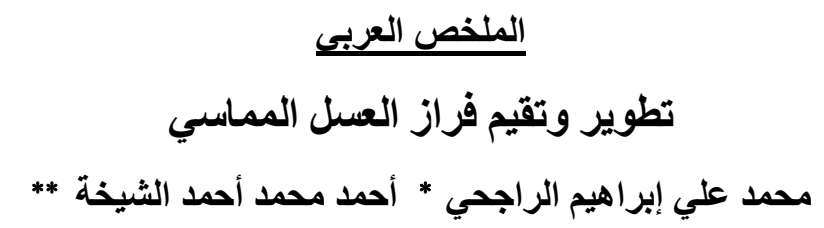

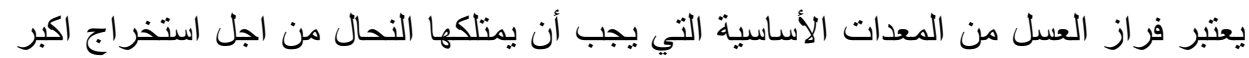

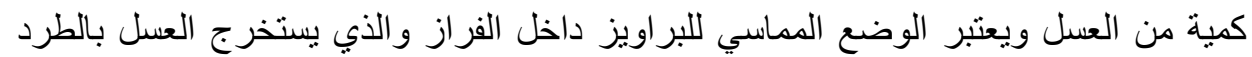

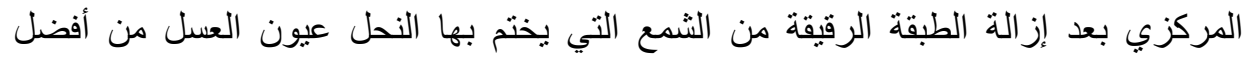

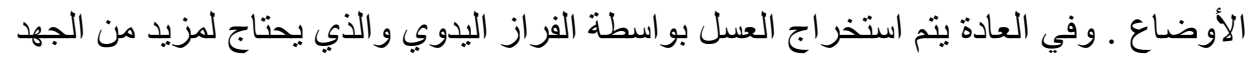

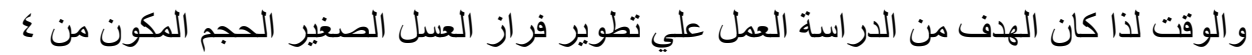

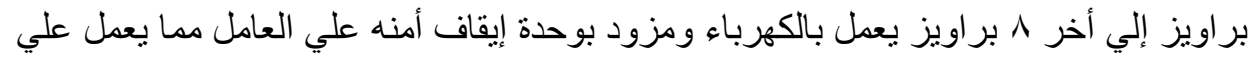

$$
\text { * * مدرث بمعهد بحوث الهندسة الزراعيةـ مركز البحوث الزراعية. }
$$


استخرج اكبر كمية من العسل في مدة زمنية اقل. وقد تمت بعض الدراسات المسبقة علي اغلب

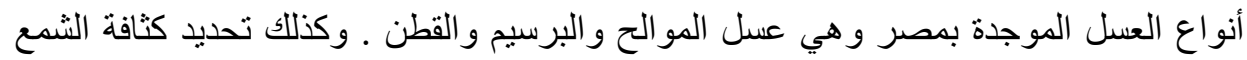

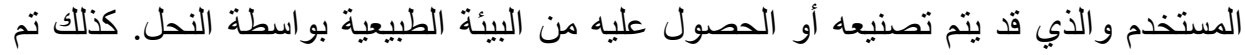

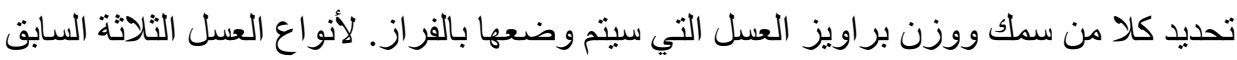

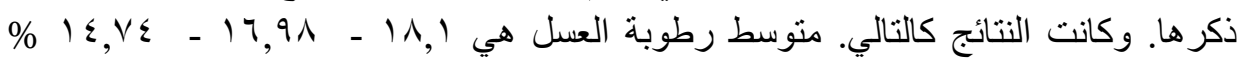

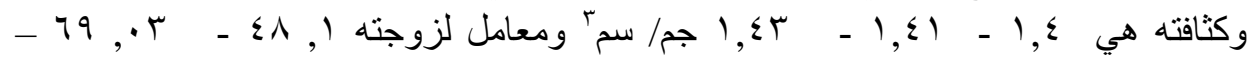

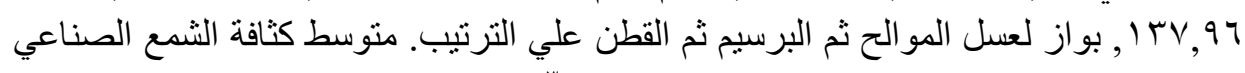

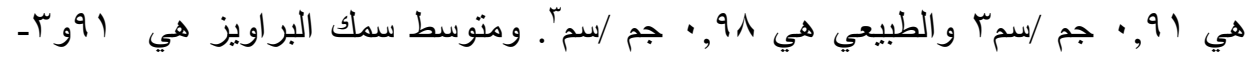
a

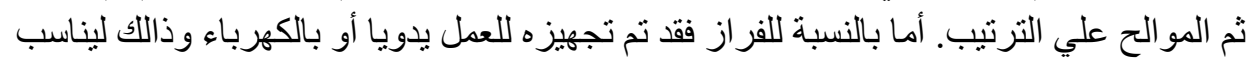

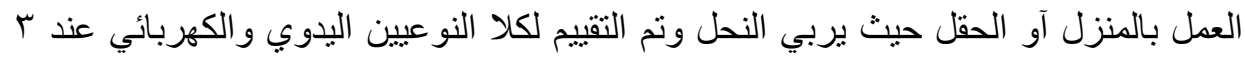

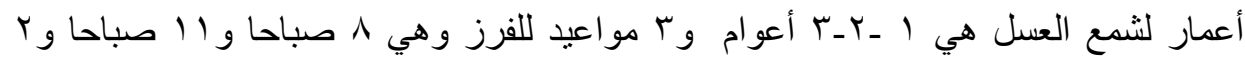

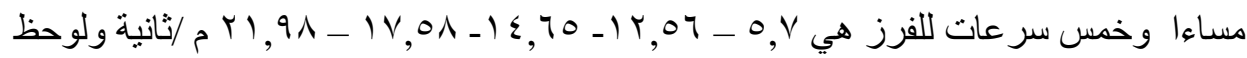

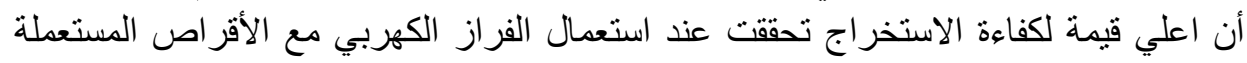

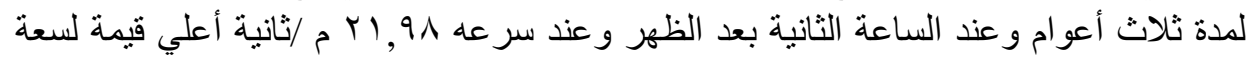

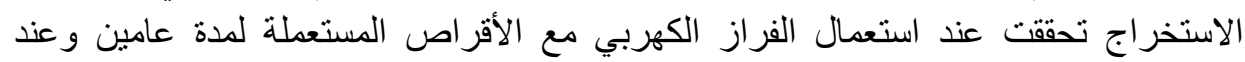

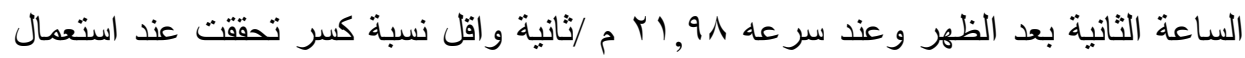

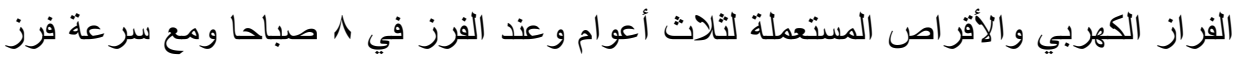

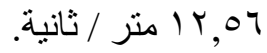

